\title{
Bumba Meu Boi sotaque Costa-de-mão pelo olhar de Nhozinho
}

\author{
Bumba my ox back-hand accent through Nhozinho's eyes
}

Walter Rodrigues Marques ${ }^{1 *}$, Flor de Cássia Pereira da Silva1², Aline Ribeiro Casas Nova de

Sousa $2^{2}$, Silvia Teresa de Jesus Pereira Dutra3 ${ }^{3}$, Hugo Leonardo Pereira Bezerra4 ${ }^{3}$, Ângela Ribeiro Casas Nova de Sousa52, Janes Claudio de Jesus Moraes6², Luis Félix de Barros Vieira

Rocha $7^{2}$

\section{RESUMO}

O artigo versa sobre o Bumba Meu Boi Sotaque de Costa-de-Mão - um dos cinco principais sotaques do Bumba boi do Maranhão. O nome do Sotaque se deu pelo fato de seus brincantes utilizarem a costa das mãos para tocarem os pandeiros. Michol Carvalho (2007) destaca que o Costa-de-Mão também é conhecido por Boi de Cururupu ou Boi de Pandeiro. A motivação pelo estudo desse sotaque se deu por ser pouco estudado em relação aos outros e, pelo fato de o estágio supervisionado (Ciências Sociais) ter sido realizado no Museu Casa de Nhozinho, nome dado em homenagem ao artista popular Antônio Bruno Nogueira (Nhozinho) - que imortalizou o Bumba-Meu-Boi Sotaque de Costa-de-Mão em seus brinquedos, suas miniaturas, que permearam toda a sua vida. A "brincadeira" é representada por Nhozinho em seus variados aspectos, seja em bonecos individuais ou em "roda". A bibliografia sobre bumba-meu-boi é ampla, mas em relação a este Sotaque, ainda é pouca. Roldão Lima (1979), Cabral (2007) são referências primárias por tratarem da vida e produção artística de Nozinho e Rodrigues (2014) por tratar exclusivamente do Sotaque Boi Costa-de-Mão. Nas referências encontradas os comentadores mencionam o Costa-de-Mão como manifestação da cultura popular maranhense de forma ampla, porém, dando ênfase aos sotaques de Orquestra, Zabumba e Matraca.

Palavras-chave: Bumba Meu Boi; Sotaque Costa-de-Mão; Cultura popular; Invisibilidade; Tradição/Modernidade.

\section{ABSTRACT}

The article is about the Bumba Meu Boi Accent of Costa-de-Mão - one of the five main accents of the Bumba boi of Maranhão. The name of Accent was given by the fact that its players use the back of their hands to play the tambourines. Michol Carvalho (2007) highlights that Costa-de-Mão is also known as Boi de Cururupu or Boi de Pandeiro. The motivation for studying this accent was because it is little studied in relation to others and because the supervised internship (Social Sciences) was held at the Casa de Nhozinho Museum, named in honor of popular artist Antônio Bruno Nogueira (Nhozinho) - who immortalized the

\footnotetext{
${ }^{1}$ SEDUC-MA (Secretaria de Estado da Educação do Maranhão)

*E-mail: walter.marques@ discente.ufma.br

${ }^{1}$ Instituto Estadual de Educação, Ciência e Tecnologia - IEMA, Bacabeira.

${ }^{2}$ SEMED (Secretaria Municipal de Educação) de Matões do Norte

${ }^{3}$ SEMED-São Luís (Secretaria Municipal de Educação de São Luís)
} 
Bumba-Meu-Boi Accent of Costa-de-Mão in his toys, his miniatures, which permeated his entire life. The "joke" is represented by Nhozinho in its various aspects, whether in individual dolls or in a "wheel". The bibliography on bumba-meu-boi is extensive, but in relation to this accent, it is still small. Roldão Lima (1979), Cabral (2007) are primary references for dealing with the life and artistic production of Nozinho and Rodrigues (2014) for dealing exclusively with the Sotaque Boi Costa-de-Mão. In the references found, commentators mention Costa-de-Mão as a manifestation of popular culture from Maranhão in a broad way, however, emphasizing the accents of Orquestra, Zabumba and Matraca.

Keywords: Bumba Meu Boi; Costa-de-Mão accent; Popular culture; Invisibility; Tradition/Modernity.

\section{INTRODUÇÃO}

O artigo é resultado de um estágio supervisionado do Curso de Ciências Sociais da Universidade Federal do Maranhão, realizado no Museu Casa de Nhozinho. A supervisão técnica do museu sinalizou que os estagiários deveriam realizar pesquisa voltada para o acervo do Museu Casa de Nhozinho. Devido ao fato de Nhozinho ter se dedicado ao Bumba meu boi Costa de Mão, a pesquisa se voltou para esse tema. O bumba meu boi do Maranhão é riqueza cultural, é popular, é da cultura popular, é do povo, é o povo. O bumba é um espetáculo de cor, sonho, ritmo, brincadeira, é chão e êxtase, é o Maranhão.

O bumba meu boi é uma manifestação da cultura popular do Maranhão que é o símbolo desta terra. O Maranhão é de uma riqueza e diversidade cultural gigante pela própria natureza. A diversidade de manifestações culturais desta terra é tão radiante quanto multifacetada. E o bumba meu boi é tanto quanto diverso em brilho, cor, ritmo, personagens e um auto que remete às relações coloniais, mas que é encenado em toda a pompa dos maiores espetáculos da Terra. O bumba meu boi é excitação desde os preparativos, ensaios, até a apresentação do auto, é um retorno atualizado do passado.

Ainda que a brincadeira ou folguedo tenha passado por atualização ou repaginação de seu enredo, de seu auto, é uma diversidade que rivaliza com a tradição e a modernidade, mas que tudo o que é feito no boi, é para apresentar o mais incandescente espetáculo, mesmo que espetacularizado, jogando com a tradição e a modernidade, a exemplo dos bois de Costa de Mão na ponta da tradição e os bois de Orquestra com os pés na modernidade.

Neste trabalho é discutido o Boi Sotaque de Costa-de-Mão e a preocupação coma perda de seus elementos tradicionais para a modernidade dos outros sotaques que buscam espetacularizar o auto. A discussão aqui empreendida não é de desqualificar os bois que 
não sejam de Costa-de-Mão, mas justamente reclamar um lugar para este tanto quanto para os outros que, como reclamam aqueles que organizam a brincadeira, percebem que maior tratamento é dado aos outros por estarem mais antenados com a modernidade como relata Padilha (2016) sobre a procura dos produtores do espetáculo escolherem determinados sotaques dando preferência aos grupos que estão voltados para a modernidade e os que primavam pela tradição ou foram esquecidos ou muito pouco procurados. Portanto, este artigo é uma forma de fazer lembrar que existe uma história, uma tradição e que ela pode andar lado a lado com a modernidade, que se pode ver as múltiplas faces do mundo tanto pelo velho quanto pelo novo, tanto pela tradição quanto pela modernidade.

Para situar o bumba meu boi, primeiramente, foi discutido os conceitos de cultura popular e o espaço do Museu Casa de Nhozinho como principal representante da cultura popular aqui discutido. Depois partiu-se para a discussão sobre políticas públicas como políticas culturais, abordando a legislação desde o âmbito federal passando pelo estadual e o municipal. Este último, analisado no município de Cururupu por Rodrigues (2014) sobre quais políticas existiam para a cultura popular e especificamente para o bumba meu boi e para quais sotaques se voltavam tais políticas.

Figura 1 - Boi de Rama Santa Sotaque de Costa-de-Mão

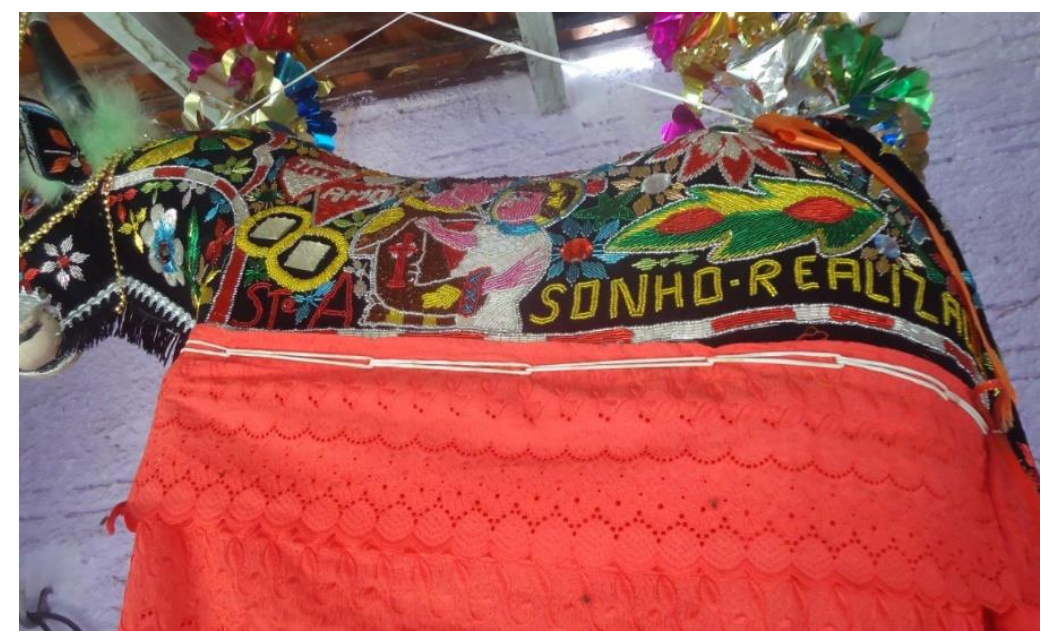

Fonte: Rodrigues (2014)

Acima fotografia do Boi Rama Santa, Boi de Sotaque Costa-de-Mão de Cururupu. Nesse sotaque, a indumentária é feita manualmente, ou seja, é bordada no coro do boi. 


\section{SOTAQUE COSTA-DE-MÃO OU BOI DE CURURUPU OU BOI DE PANDEIRO VERSUS INVISIBILIDADE/ESQUECIMENTO}

Rodrigues (2014) destaca que em Cururupu existe o Boi Rama Santa, o Boi Brilho da Sociedade ou da Fortaleza e o Boi de Areia Branca. Existem várias situações para o aparecimento e desaparecimento dos grupos de bumba-meu-boi, o que pode justificar o desencontro do que abaixo consta (dezessete grupos).

em Cururupu pontificam dez grupos, sendo três Bois de Areia Branca, Boi do Barro Vermelho, Boi Rama Santa, Boi da Taguatinga, Boi Mané Rabo, Boi de Adosia, Boi de Marcelo Pimenta, Boi da Fortaleza ou Brilho da Sociedade; em Serrano do Maranhão atuam dois conjuntos: Boi da Solenidade e Boi de Antônio Nhá Nhá; em Buriti, também, brincam dois grupos: Boi Bela Rama e Boi de Luís Alves; em São Luís existem três cinjuntos que mantém vivo este estilo da brincadeira: Boi Sociedade de Cururupu, Boi do Bairro Novo e Boi Mimo do Santo, sendo este último um grupo infanto-juvenil (CARVALHO, 2007, p. 44-45).

Rodrigues (2014) destaca as ações sociais realizadas pela Associação Recreativa e Cultural do Boi Rama Santa, boi o qual é o objeto de sua pesquisa monográfica. A pesquisa detém-se na dicotomia tradição/modernidade (utilizando as concepções de Ester Marques sobre o tema), quais perdas e ganhos o sotaque sofreu com as transformações ao longo do tempo. Tendo em vista que o Sotaque de Costa-de-Mão vem sendo um dos mais relegados ao esquecimento pela sociedade, que se volta para a modernidade, Rodrigues investigou as políticas públicas e/ou culturais (no âmbito federal, estadual, municipal) que buscasse resgatar o fomento do Sotaque enquanto tradição cultural local e constatou que a prefeitura de Cururupu não tem uma política pública voltada para esse resgate e manutenção da manifestação cultural do Boi de Costa-de-Mão, salvo alguma ajuda por ocasião dos festejos juninos. Contudo, a ajuda a outros grupos, de outros Sotaques parece ser maior, conforme fontes da pesquisadora. Situação análoga ao Boi Costa-de-Mão em relação a falta de políticas públicas, perdas da cultura popular, portanto, a memória e a tradição, é investigado, também num trabalho monográfico do ano de 2016, o Bumbameu-Boi no município de São Bernardo, Maranhão por Leia Meireles Pereira.

Por se tratar de um trabalho monográfico para conclusão do curso de Educação Artística, a pesquisa de Rodrigues se voltou para a escola colocando o Sotaque como conteúdo da disciplina Arte no currículo. A pesquisadora constatou que o Sotaque é trabalhado em algumas situações específicas, como datas comemorativas ou projetos integradores escolares. Para entrelaçar o trabalho artístico de Nhozinho, voltou a pesquisa para Museu Casa de Nhozinho com a coleção deste artista popular sobre o Bumba boi 
Sotaque Costa-de-Mão, detendo-se em bibliografias como Roldão Lima e Lélia Coelho Frota Cabral que situam Nhozinho e o Boi Costa-de-Mão.

Figura 2 - a roda (de Nhozinho)

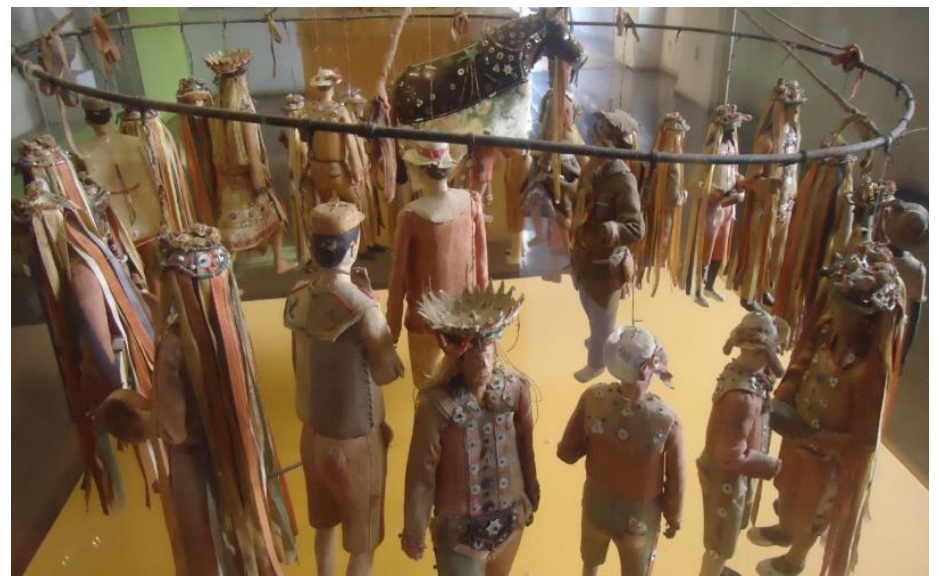

Fonte: Rodrigues (2014)

A partir dos elementos já citados, Rodrigues (2014) parte para a análise do processo de montagem da brincadeira, dos ensaios ao ritual da morte do Boi. As toadas, o batismo, os personagens, a indumentária, as cores e texturas, o bordado, os instrumentos, para botar o Boi para brincar.

Se deseja vê o nosso boi brincar, eu também.

Faz um tempo que não te vejo.

Para te olhar uma brincadeira boa, vem para o Rama Santa ficar a vontade, boi alinhado.

O nosso objetivo é te fazer feliz.

Toada de "chegada” João Abreu- Bumba boi Rama Santa (RODRIGUES, 2014)

Figura 3 - Pedraria do chapéu de fita

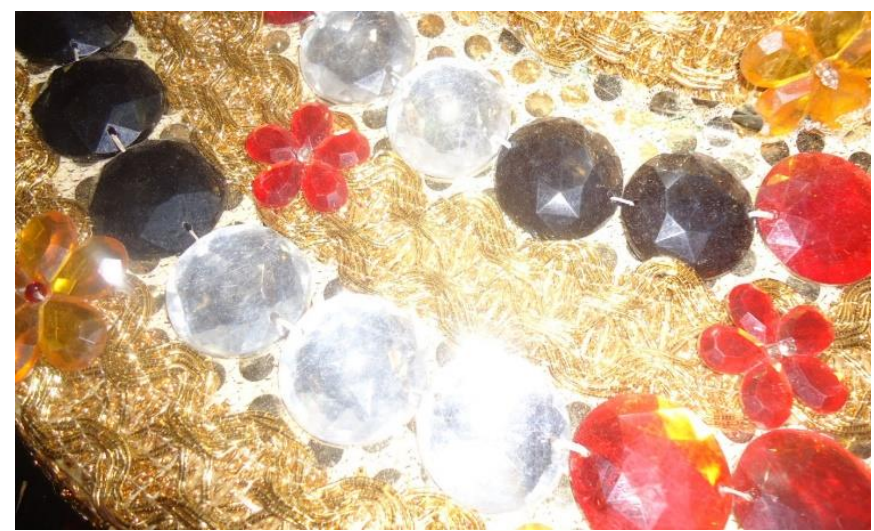

Fonte: Rodrigues (2014) 
O livro "Vida e arte de Nhozinho" é resultado de trabalho monográfico de Roldão Lima sobre esse homem tão importante para a cultura popular maranhense. O texto é bastante explicativo e didático, traz relatos minuciosos da vida e da arte dessa ímpar figura de nossa cultura popular.

Lima (1979) destaca a personalidade de Antônio Bruno Pinto Nogueira - o Nhozinho - como uma pessoa difícil de lidar, um artista nato e muitíssimo inteligente e criativo, birrento, de opinião própria, que vivia cercado de crianças, namorador, companheiro, e um homem que adorava produzir, mas não ligava para o dinheiro. Nhozinho gostava muito de ajudar as pessoas, queria servir, mas detestava pedir algo emprestado. Nhozinho se negava veementemente a empreender um museu para sua produção, pois dizia que seu trabalho era para ser vendido e não confinado em um museu. Apresenta-se aqui a ideia de que museu é lugar de coisa velha, depósito.

"A arte de Nhozinho destaca-se como um dos mais importantes momentos da produção estética, de caráter popular, no Maranhão" (LIMA, 1979, p. 21). Nhozinho nasceu em Bacuripanã (no distrito de Cururupu) em 17 de maio de 1904 e morre em São Luís em 23 de maio de 1974. Nhozinho chega a São Luís em 1936, então com 32 anos de idade. Um destaque de Lima (1979) sobre Nhozinho é o fato de estar sempre cercado por crianças, o que marcou toda a sua vida.

Nhozinho inicia seus trabalhos construindo barquinhos de buriti e carrinhos-deboi de madeira. A base inspiradora de Nhozinho foi o folguedo do bumba-meu-boi e cuja evolução e fases tanto do folguedo quanto do trabalho artístico com o domínio da técnica com a consequente depuração da realização plástica. Nhozinho extrapolou os limites da mera estilização exprimindo uma recriação na busca do dinamismo, cores, brilho e emoções que o bumba-meu-boi traz na brincadeira. A evolução do trabalho escultural de Nhozinho parte das esculturas imóveis, com feições rígidas - estático. Este trabalho diz de uma época popular de quando a brincadeira era realizada, vestidas apenas com papel de seda. Os antigos diziam que o boi brincava sem canutilhos, miçangas ou paetês, que só “depois é veio todo esse brilho - informam, sem remorso" (LIMA, 1979, p. 24). Parece aqui que estão dizendo que o boi está perdendo sua essência; num segundo momento, já há uma tentativa de dar movimento às figuras, "de dotar os bonecos de gestos como por exemplo curvar as pernas, levantar os braços, fumar, segurar instrumentos na posição de bater" (LIMA, 1979, p. 25); e, finalmente, um terceiro momento, onde Nhozinho mostra 
"toda a sua criatividade e capacidade artística" que é a explosão "na ritimização das personagens do bumba-meu-boi feitas de buriti, dando-lhes, [...] ânimo e sentido de vida. [...], 'nas suas rodas de boi'”' (LIMA, 1979, p. 25).

Bacuripanã é um "lugar de comércio, lavoura, embarcações de frete e pescaria", onde "Nhozinho começou muito cedo a construir barquinhos. Em Cururupu, "fazia caixinhas, barcos e papagaios, árvores, animais de toda espécie e pontes em miniatura, que vendia para a ornamentação de presépios" (LIMA, 1979, p. 79). Nhozinho inicia seu trabalho em madeira e depois resolve entalhar em buriti as "figuras do bumba-meu-boi, que sempre apresenta graciosamente arrumados em roda" (LIMA, 1979, p. 80). Mestre Vitalino que, no artesanato de Caruaru, Pernambuco, desapareceu, "reaparece no Maranhão através de Nhozinho que faz bonecos em madeira macia de buriti" (LIMA, 1979, p. 80).

Nhozinho pode ser definido enquanto artista, em três fases: a primitiva, onde é só um artesão; a estática, onde as figuras são imóveis; e a atual, onde as figuras apresentam proporção em movimento (LIMA, 1979). Dona Zelinda Lima, em entrevista a Roldão Lima, menciona o Bumba-Meu-Boi de Costa-de-Mão em resposta a perguntas dele sobre se Nhozinho teria incluído aspectos do Boi de Cururupu em seus trabalhos. Então ela responde:

Muito. Na indumentária, nos adereços, tudo completamente diferente dos
outros estilos. É puramente boi de Cururupu. É o boi de pandeiro-de-costa-de-
mão (pequenos pandeiros percutidos com a costa das mãos). A grinalda dos
chapéus é só na frente e é trabalhada em malacacheta. [...], mas como foi
desaparecendo de venda, ele introduziu o papel laminado (LIMA, 1979, p. 58).

Em todo o trabalho de Roldão Lima, que é uma biografia de Nhozinho, o Boi está muito presente. Até porque, a história de Nhozinho perpassa, quando passa a fazer os boizinhos, pelo Boi de sua infância que é o de Sotaque de Costa-de-Mão ou Boi de Pandeiro, mas a menção ao Sotaque propriamente dito, só aparece no trabalho na referida fala de Dona Zelinda Lima a seu interlocutor Roldão Lima.

Não aparecem no decorrer do trabalho, nenhuma referência ao termo em trabalhos anteriores sobre o estudo do Boi de Sotaque de Costa-de-Mão. De acordo com Martins (2015), na década de 1940 já existiam outros sotaques independentes dos três ditos principais, embora pouco conhecidos, sendo mencionado os sotaques de Pindaré e Cururupu somente em 1980 por José de Ribamar Reis. 
Michol Carvalho (2007) destaca um Boi onde só homens podem ser vaqueiros, assim como um Boi de gente simples e que brincam sem toda a pompa dos outros sotaques, ou pelo menos, era assim no início, com roupas simples, se comprava o tecido pela manhã e à noite já estavam na Brincadeira. Como relatam alguns botadores de Boi, não tinha esse luxo todo de hoje.

Michol Carvalho (2007) registra 250 Bois de Sotaque de Costa-de-Mão no Estado do Maranhão (Dados da Comissão Maranhense de Folclore). A manifestação do Bumbameu-Boi já foi considerada marginal no Estado do Maranhão. Como destaca a autora, o Boi teve que superar muitas barreiras de preconceitos por "ser "uma brincadeira de negros, de gente simples e pobre', e a 'Brincadeira' era considerado pelas elites como um atentado "à boa ordem, à civilização e à moral, chegando a ser proibida no período de 1861 a 1867”. Havia limites para o Boi, não podia ultrapassar os limites da cidade, ou seja, só podia avançar até o João Paulo, o que vai mudar a partir de 1960 com o avanço das políticas para a cultura.

O Sotaque de Cururupu tem como principal berço o município de Cururupu e os municípios vizinhos Serrano do Maranhão e Bacuri (foram desmembrados, por isso herdaram o Sotaque). Em 2007 havia dezessete grupos do Sotaque Costa-de-Mão

em Cururupu pontificam dez grupos, sendo três Bois de Areia Branca, Boi do Barro Vermelho, Boi Rama Santa, Boi da Taguatinga, Boi Mané Rabo, Boi de Adosia, Boi de Marcelo Pimenta, Boi da Fortaleza ou Brilho da Sociedade; em Serrano do Maranhão atuam dois conjuntos: Boi da Solenidade e Boi de Antônio Nhá Nhá; em Buriti, também, brincam dois grupos: Boi Bela Rama e Boi de Luís Alves; em São Luís existem três cinjuntos que mantém vivo este estilo da brincadeira: Boi Sociedade de Cururupu, Boi do Bairro Novo e Boi Mimo do Santo, sendo este último um grupo infanto-juvenil (CARVALHO, 2007, p. 44-45).

Os Bois de Costa-de-Mão "não botam o Boi todo ano", pois dependem da promessa, do revezamento dos brincantes ou mesmo do surgimento de novos bois (CARVALHO, 2007, p. 45; RODRIGUES, 2014). Umbelino Pimenta compara o Boi ao gado comum, "pé duro" ("raças encontradas no Maranhão"). O Boi de Cururupu apresenta uma peculiaridade quanto ao

seu bordado em alto relevo devido ao uso de pedraria e, também, da técnica de bordar as figuras em um pedaço de veludo a parte, pregando, depois, no couro como se fosse um enxerto, ou ainda, pelo salpicado que repete várias vezes um motivo fora do desenho central, para preencher certos espaços do veludo. Assim, o bordado parece saltar do couro ...E, os motivos escolhidos para o bordado são muitos: santos, cenas bíblicas, paisagens, pessoas, flores, animais, figuras sobrenaturais... (CARVALHO, 2007, p. 46-47). 
Uma característica que diferencia o Costa-de-Mão é a barra comprida da roupa. O Bumba Meu Boi do Maranhão é símbolo identitário do maranhense (CARVALHO, 2007). Os motivos para botar a brincadeira partem de um enredo que pode ser real ou fictício - temas da comunidade, corriqueiro ou que passam na TV, como o Bin Laden (CARVALHO, 2007).

\section{CONSIDERAÇÕES FINAIS}

A bibliografia sobre o bumba meu boi do Maranhão é bem ampla. E a escolha pelo Sotaque de Costa-de-Mão se deu, em primeiro lugar, pelo fato de que este sotaque é desprezado pelos agentes públicos que valorizam demasiado os sotaques da espetacularização; em segundo lugar por estar estagiando em um museu que detém a maior representação de um bumba meu boi, como as rodas, feita por um artista popular em forma de brinquedos sobre o sotaque; em terceiro, por uma identificação com o resgate de uma manifestação da cultura popular que ainda preza pela originalidade e autenticidade. Não que a espetacularização seja um mal, que só a tradição deva ser considerada, todos são apreciativos e o espetáculo é fabuloso, mas as entranhas do boi também devem ser vividas como nos tempos de outrora.

Poucos são os trabalhos feitos exclusivamente sobre o Boi Sotaque Costa-de-Mão, sendo encontrada para este trabalho apenas a monografia de Wenna Késsia Mendes Rodrigues de 2014 da Universidade Federal do Maranhão. Longe de querer esgotar o tema e a busca, mas na internet, inclusive no NIB/UFMA não foi reportado outro trabalho específico sobre o Sotaque. O que se pode destacar é que em geral os autores e comentadores do bumba-meu-boi do Maranhão ressentem-se de políticas culturais para o boi, especialmente, o de Costa-de-Mão. 


\section{REFERÊNCIAS}

CARVALHO, Maria Michol Pinho de. Nhozinho: imensas miudezas. [pref. de Ferreira Gullar; trad. Alba Regina Serpa Lírio; organização Heloisa Nascimento Alves, Alice Cavalcante Lima e Silva]. - Rio de Janeiro: Sábios Projetos, 2007.

CABRAL, Lélia Coelho Frota. Nhozinho: imensas miudezas. [pref. de Ferreira Gullar; trad. Alba Regina Serpa Lírio; organização Heloisa Nascimento Alves, Alice Cavalcante Lima e Silva]. - Rio de Janeiro: Sábios Projetos, 2007.

LIMA, Roldão. Vida e arte de Nhozinho. FUNC/SIOGE/MARATUR. - São Luís. SIOGE, 1979.

MARQUES, Francisca Ester de Sá. Tradição e modernidade no Bumba-Meu-Boi. In: NUNES, Izaurina Maria de Azevedo (org.). Olhar, memória e reflexões sobre a gente do Maranhão. - São Luís: Comissão Maranhense de Folclore, 2003.

MARTINS, Carolina Christiane de Souza. Política e cultura nas histórias do bumbameu-boi: São Luís do Maranhão - século XX. 2015. 160 f. Dissertação (Mestrado em História Social), - Programa de Pós-Graduação em História Social, Universidade Federal Fluminense, Niterói. 2015.

NUNES, Izaurina Maria de Azevedo (org.). Olhar, memória e reflexões sobre a gente do Maranhão. - São Luís: Comissão Maranhense de Folclore, 2003.

PADILHA, Antônio Francisco de Sales. Bumba meu boi e assimetria social no Maranhão. In: Repocs, v. 13, n. 25, jan/jun, 2016, p. 207-224.

PEREIRA, Leia Meireles. Memória e escrita na tradição popular: da oralidade do boi de pano à escrita do bumba meu boi contemporâneo no município de São Bernardo, Maranhão. 2016. 33 f. (Graduação em Linguagens e Códigos/Língua Portuguesa), Curso de Graduação em Linguagens e Códigos/Língua Portuguesa, Universidade Federal do Maranhão, São Luís. 2016.

RODRIGUES, Wenna Késsia Mendes. Bumba Boi Costa de Mão de Cururupu - um olhar sobre o processo histórico e artístico em diversos aspectos sociais, culturais e educacionais. 2014. 70 f. (Graduação em Educação Artística), - Curso de Educação Artística, Universidade Federal do Maranhão, São Luís. 2014. 